\title{
A Statistical Comparison of the Implementation of Concurrent Engineering in Jordanian Industry
}

\author{
Mohammad D. Al-Tahat', Ala'a M. Al-Habashneh1, Issam S. Jalham² \\ ${ }^{1}$ Industrial Engineering Department, the University of Jordan, Amman, Jordan \\ ${ }^{2}$ School of Engineering, the University of Jordan, Amman, Jordan \\ Email: altahat@ju.edu.jo,habashneh_alaa@yahoo.com
}

How to cite this paper: Al-Tahat, M.D., Al-Habashneh, A.M. and Jalham, I.S. (2019) A Statistical Comparison of the Implementation of Concurrent Engineering in Jordanian Industry. Open Journal of Statistics, 9, 361-372.

https://doi.org/10.4236/ojs.2019.93025

Received: May 26, 2019

Accepted: June 27, 2019

Published: June 30, 2019

Copyright $\odot 2019$ by author(s) and Scientific Research Publishing Inc. This work is licensed under the Creative Commons Attribution International License (CC BY 4.0).

http://creativecommons.org/licenses/by/4.0/

\section{Open Access}

\begin{abstract}
In this paper, a statistical comparative investigation of the implementation of Concurrent Engineering (CE) in Jordanian Industry is introduced, practices of $\mathrm{CE}$ are reviewed, then mapped into six statistical latent. A Structural Equation Model (SEM) is developed for the implementation of CE, then the model is applied to the following Jordanian industrial sectors: chemical and cosmetics industries, engineering and electrical industries and information technology, wood and furniture industries, and construction industry. The implementation level for the six CE practices among the selected sectors is investigated; a statistical comparative analysis between the considered industrial sectors is conducted. Thereafter, a system dynamics model is developed to understand the true CE trade-offs, which is used as a validity measure to insure that the proposed statistical model and hypotheses are valid.
\end{abstract}

\section{Keywords}

Concurrent Engineering, Structural Equation Model, SEM, System Dynamics, Jordan, Social Statistics

\section{Introduction}

Authors continuously applying different methodologies searching for solutions improve the performance of operations and systems from multiple aspects. AL-Tahat M. D. considered the Japanese Kanban methodology to formulate a production line as a queuing network model [1]. A study was conducted by Al-Momani K. R. et al. [2] in order to assess the needs of performance improvement of maintenance effectiveness measures improvement of the health 
care services; for in King Abdullah University Hospital (KAUH). Al-Refaie A. et al. [3] examined the factors that affect firm performance using structural equation modeling; they developed a structural model that includes several latent, including knowledge management, organization learning, customer relationship management, employee performance, innovation and business performance. AL-Tahat M. D. et al. [4] presented an Activity-Based Cost Estimation Model for better estimation of the cost of producing steel castings in a foundry system. A model to estimate the weights of mutually dependent criteria, based on cause-effect assessments of a group of professionals, is developed by Dalalah D. et al. [5] for problem of multiple criteria decision making (MCDM). For pharmaceutical industry, Al-Tahat M. D. et al. [6] used an Ordinal Logistic Regression Modeling (OLRM) to predict and to investigate the relationship(s) between the different types of failures encountered in tablet production and the relevant tablet- and punch attributes. Mohammad D., Al-Tahat et al. [7] presented a model of a multi-phase multi-product manufacturing system considering a constant work-in-process (CONWIP) control mechanism using continuous-time Markov chain modelling approach; the analyses explain a foundation needed for analyzing the steady state behavior of manufacturing systems. For microsystem technologies, Aljanaideh O. et al. [8] suggested a new hysteresis model that can describe rate and bias effects of the harmonic magnetic fields on hysteresis nonlinearities of a magnetostrictive actuator. The model characterized the asymmetric hysteresis effects under different levels of input magnetic bias. Unlike the aforementioned methodologies, authors in this paper presented another methodology for performance improvements, Concurrent Engineering (CE) is introduced, and then a Structural Equation Model (SEM) is developed for the implementation of $\mathrm{CE}$ in some Jordanian industrial sectors.

Concurrent engineering (CE) appeared in the 80 's as a thought parallel to continual improvement methodologies of engineering design activities. This concept is based on common assumption that different parts of product life cycle considered together and early in the development process, by using different methods and tools to support engineering and development activities [9]. First, let us begin by defining what a CE is. Herder, P.M. et al. [10] defined CE as a systematic approach to the integrated, concurrent design of products and their related processes, including manufacture and support. The developers, from the outset, consider all elements of the product life cycle from conception through disposal. Yassine and Braha [11] defined CE as an engineering management philosophy and a set of operating principles that guide a product development process through an accelerated successful completion. To have shorter development time, improved product quality, and lower development and production costs, the incorporation of downstream concerns into the upstream phases of a development process must be considered. Alemu Moges [12] defined it as, a conceptual framework that acts as an umbrella to all design improvement tools and techniques. Companies tend to reveal the following $\mathrm{CE}$ principles, which can contribute to time reduction, cost reduction, improve product quality and fulfil customer's need: 1) integration, 2) 
concurrency, 3) people, 4) process, 5) instruments and technology.

This paper aims to: 1) provide a statistical comparative investigation of the implementation of CE in Jordanian Industry, 2) provide a dynamics model for better understanding of the effects of CE on industry.

\section{Statistical Latent of the Proposed Model}

Concurrent Engineering is supposed to involve six-construct latent listed in Table 1. These are Client Participation, Business Administration, Organizational Data Structure, Suppliers Participation, Value Stream Distribution, and Multi-Skill Training. The following sub-section describes briefly each of these latent.

\subsection{Client Participation (CP)}

Firms depend on acquiring markets; with products, that customer needs [13]. Firms have found a number of techniques to capture customer requirements, sharp market understanding, and feedback from buyers, warranty and adding clients to the product development team, and ensure a sustainable process innovation are essential to gain more customs attentions [14].

\subsection{Business Administration (BA)}

Business Administration (BA) is a common management style for modern small businesses. Administration allows managers to break down the entire operations

Table 1. Mapping of CE practices into six-construct latent.

\begin{tabular}{|c|c|c|}
\hline CE Dimension & Identifier & CE Practices \\
\hline \multirow{4}{*}{$\begin{array}{c}\text { Client } \\
\text { Participation }\end{array}$} & \multirow{4}{*}{$\mathrm{CP}$} & Warranty \\
\hline & & Mutual trust feedback \\
\hline & & Sharp market understanding \\
\hline & & Adding customers to the product \\
\hline Business & \multirow{2}{*}{$\mathrm{BA}$} & Teams \\
\hline Administration & & Management \\
\hline \multirow{2}{*}{$\begin{array}{l}\text { Organizational Data } \\
\text { Structure }\end{array}$} & \multirow{2}{*}{ ODS } & Sharing information \\
\hline & & Successful communication \\
\hline \multirow{3}{*}{ Multi-Skill Training } & \multirow{3}{*}{ MST } & Functional job \\
\hline & & Teams responsibilities \\
\hline & & Environment of mutual trust \\
\hline \multirow[t]{3}{*}{$\begin{array}{c}\text { Suppliers } \\
\text { Participation }\end{array}$} & \multirow[t]{2}{*}{ SP } & $\begin{array}{l}\text { Treated suppliers as an } \\
\text { extension of the organization }\end{array}$ \\
\hline & & knowledge innovation \\
\hline & \multirow[b]{2}{*}{ VSD } & Technologies supporting workflow \\
\hline $\begin{array}{l}\text { Value Stream } \\
\text { Distribution }\end{array}$ & & $\begin{array}{l}\text { Concurrent workflow and } \\
\text { distribution management }\end{array}$ \\
\hline
\end{tabular}


of a department into several phases. Dividing operational functions into sections allows management to obtain a clear picture of what the goals of a department are and how to implement the goals most effectively. Administration also allows managers to respond rapidly to factors that affect the internal or external expectations of company.

\subsection{Organizational Data Structure (ODS)}

When the Organizational Data Structure (ODS) is not balanced, the process of collaboration can break down, and the development teams can lose their effectiveness. According to Willaert et al. [15], an unwell integrated ODS environment means that communication problems between departments will cause lengthy delays in development time and increased costs. A team cannot exist without communication, to make the team concept work; therefore, technical information had to be more accessible to all parties involved in the organization [13].

\subsection{Multi-Skill Training (MST)}

A good team has the foresight to identify, address, and resolve issues through the entire product life cycle. Multi-Skill Training (MST) performance is important for the success of any CE initiative. Teams with team leaders whose functional jobs and team responsibilities have a high degree of overlap tend to be the most successful [16]. A key step in the successful use of teams is training. Training can help speed team effectiveness [17].

\subsection{Business Administration (BA)}

A successful supplier relationship management model implies; few suppliers, suppliers' involvements, an environment of mutual trust, and treated suppliers as an extension of the organization [18].

\subsection{Value Stream Distribution (VSD)}

Value stream distribution (VSD) provides optimum value to customers through a complete value creation process with minimum waste. Supporting technologies for VSD include; work process modeling, performance analyzing, re-engineering, redesign of processes, and tasks monitoring. For the successful application of workflow, it is essential that there be a good fit between work practice and the models/mechanisms used by the VSD system.

\section{Structural Equation Model (SEM) and Statistical Hypotheses}

The statistical relationship between the components of the proposed SEM model is shown in Figure 1. Six main elements are included. The model investigates the importance of the statistical relationships between the six CE practices and the impacts of their implementations on the industry. For data collection, a questionnaire was developed, the questionnaire was tested and reviewed by; managers of several manufacturing firms, academic professors, and extensive literature 
review. A pretest pilot study conducted on sample size of 20 to test the questionnaire clarity, comprehensiveness, wording of questions, and level of sophistication of language and appropriateness of the content [19]. The questionnaire consists of five-point Likert-scale, anchored at 1) "poor", 2) "fair", 3) "good", 4) "very good", and 5) "excellent". A sample with a proper size is selected; the sample covers the following industries: therapeutic industries and medical supplies, plastic and rubber industries, chemical and cosmetics industries, engineering and electrical industries and information technology, wood and furniture industries, construction industry, packaging and paper industries, food and agricultural industries.

\section{Data Collection and Analysis}

Jordanian companies were screened according to whether they have a potential of implementing CE tools or not, the developed questionnaire was distributed to the industrial sectors concerned to apply CE more than others, these sectors are: 1) construction industry, 2) engineering and electrical industries and information technology, 3) chemical and cosmetics industries, and 4) wood and furniture industries. The sample size of those sectors is 492 . Feedback of 310 respondents is collected; statistical analysis has been carried out using IBM SPSS version 22. For the developed Structural Equation Model (SEM), ANOVA, Validity, Multicollinearity, internal consistency, and relationships between CE elements and tools are tested, thereafter; the causal relationships of CE elements and their impact on the performance of industrial enterprises are investigated.

\subsection{Validity and Reliability}

The Cronbach's alpha coefficient [20] is used to evaluate the internal reliability of the developed SEM. It measures the internal consistency of the items of the questionnaire [21], the higher this coefficient, the better the measuring instrument. As shown in Table 2, Cronbach's alpha value of the whole CE practices is equal to 0.718 .

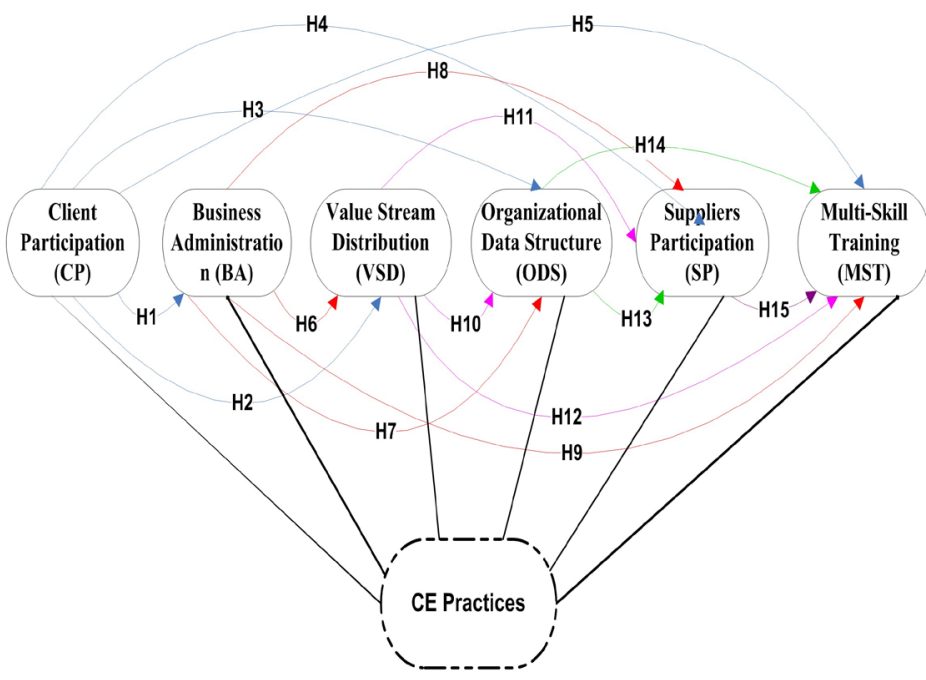

Figure 1. Proposed conceptual model and research hypotheses. 
Table 2. Cronbach's alpha for each latent.

\begin{tabular}{cc}
\hline Item & Cronbach's Alpha $(\alpha)$ \\
Customer involvement & 0.832 \\
Organization management & 0.663 \\
Information infrastructure system & 0.742 \\
Supplier involvement & 0.674 \\
Workflow distribution & 0.711 \\
Cross functional team & 0.687 \\
Overall & 0.718 \\
\hline
\end{tabular}

It is observed that the implementation level for the six CE practices among the selected sectors is ranged between $60.37 \%$ and $60.70 \%$. Best and worst implementer among the ten sectors is illuminated in Table 3.

For CP practice, Construction sector has achieved the best implementation index because construction sector considers the premise that the customers know what they want and what they need, during the definition phase, there is a customer's self-understanding about the project's objectives, and confront the customer's desires by exploring alternatives that were not previously considered [22]. However, engineering industries exhibits the worst implementation index because practices such as sharp market understanding, and feedback from buyers are rarely used in this sector, also gathering relevant customer knowledge in the front end of new product development to enable solid strategies therefore remains a challenge.

On the other hand, for BA practice, wood sector has accomplished low index because of the lack of slack resources, a goal of lean centralized organizational designs, and an inward communication climate. In contrary, chemical sector is classified as the best implementer for BA because in the case of construction the lack of fit between the type of infrastructure available and the needs of society [23].

For ODS wood sector has earned the best implementation index, while construction sector is the worst. For SP wood sector has earned the best implementation index, while engineering sector is the worst. VSD engineering sector has earned the best implementation index, while chemical sector is the worst.

Finally, engineering sector is the best implementer for MST, because training started at the beginning of implementation stage and there is a flexible training option. However, construction sector has achieved the worst implementation level.

\subsection{Comparative Investigation of Model Relations}

The estimates of the relations between models constructs for chemical and cos- 
metics industries sector, engineering and technology, construction as well as wood and furniture are shown in Figures 2-5 respectively.

Table 3. Best and worst CE implementer.

\begin{tabular}{ccc}
\hline Practice & Best Implementer & Worst Implementer \\
\hline CP & Construction & Engineering \\
BA & Chemical & Wood \\
ODS & Wood & Construction \\
SP & Wood & Engineering \\
VSD & Engineering & Chemical \\
MST & Engineering & Construction \\
\hline
\end{tabular}

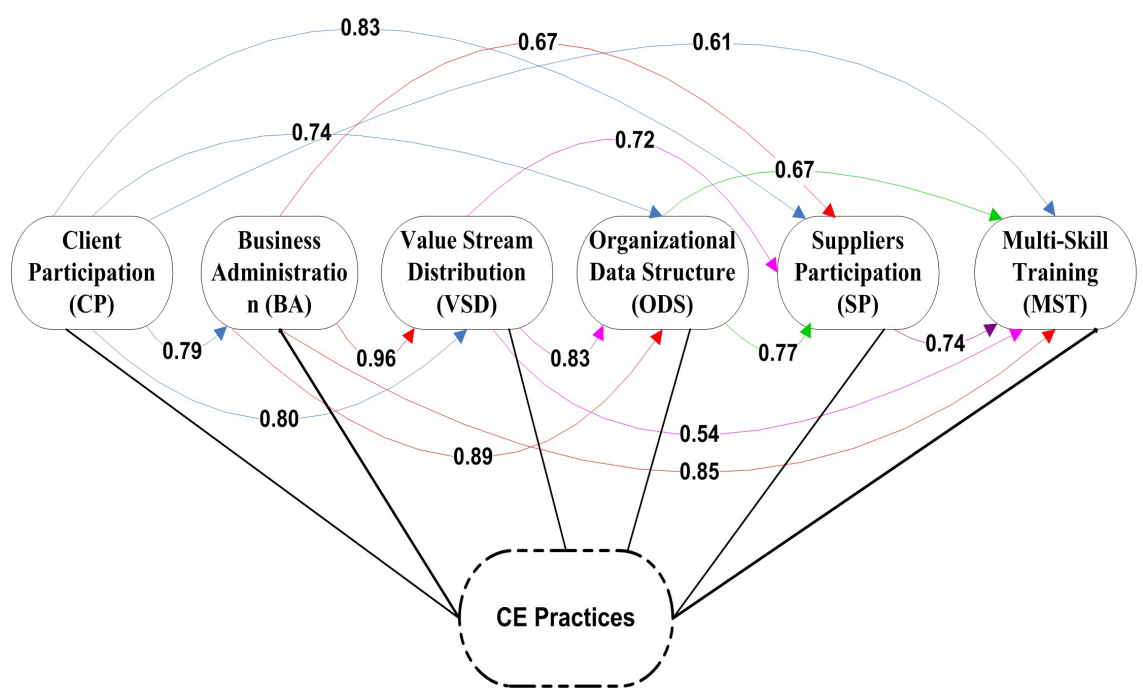

Figure 2. Estimates of relations for chemical and cosmetics industries sector.

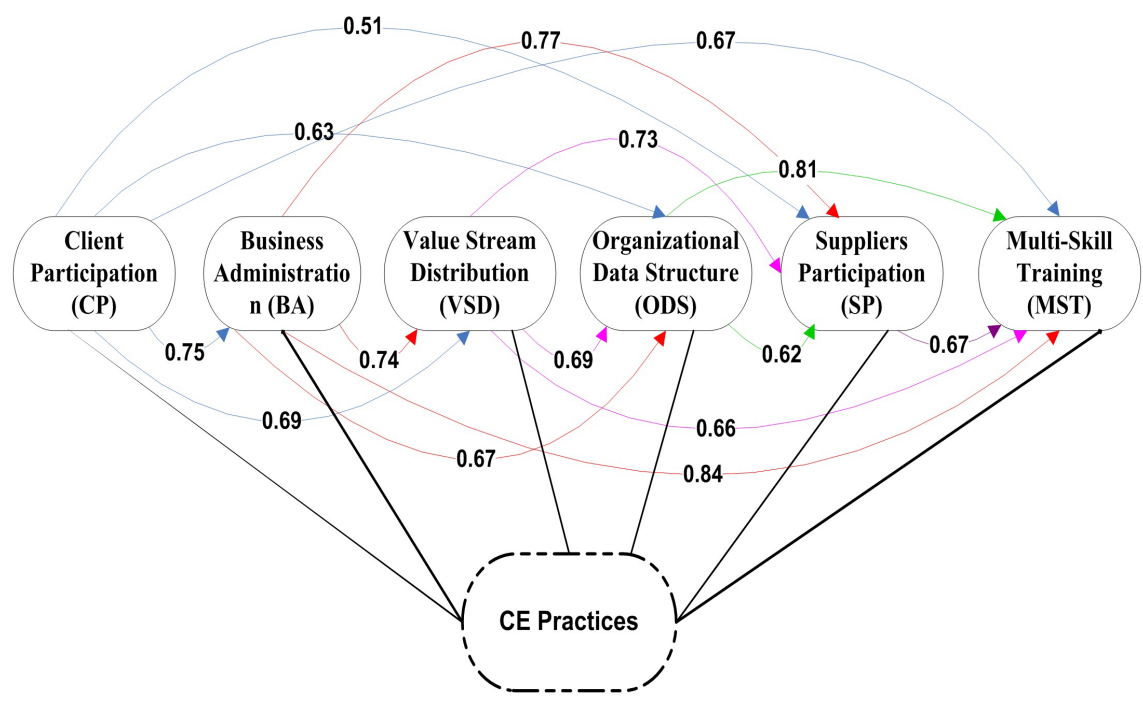

Figure 3. Estimates of relations for the engineering, electrical industries and information technology sector. 


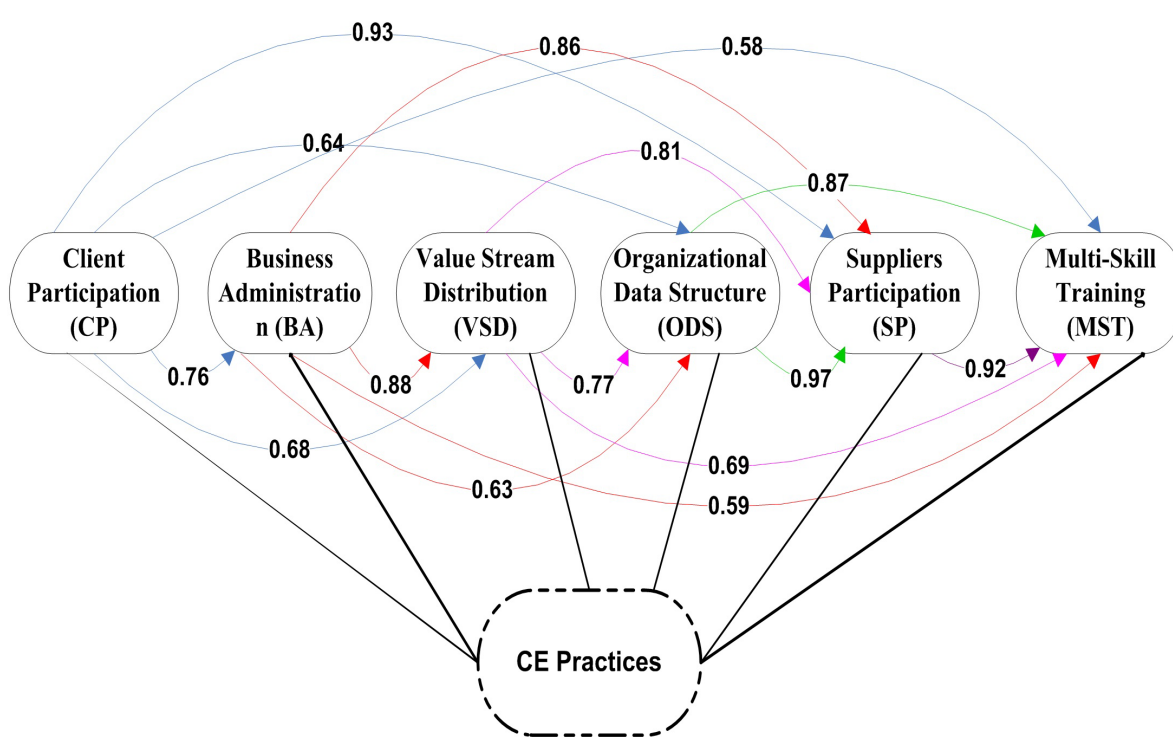

Figure 4. Estimates of relations for construction industry.

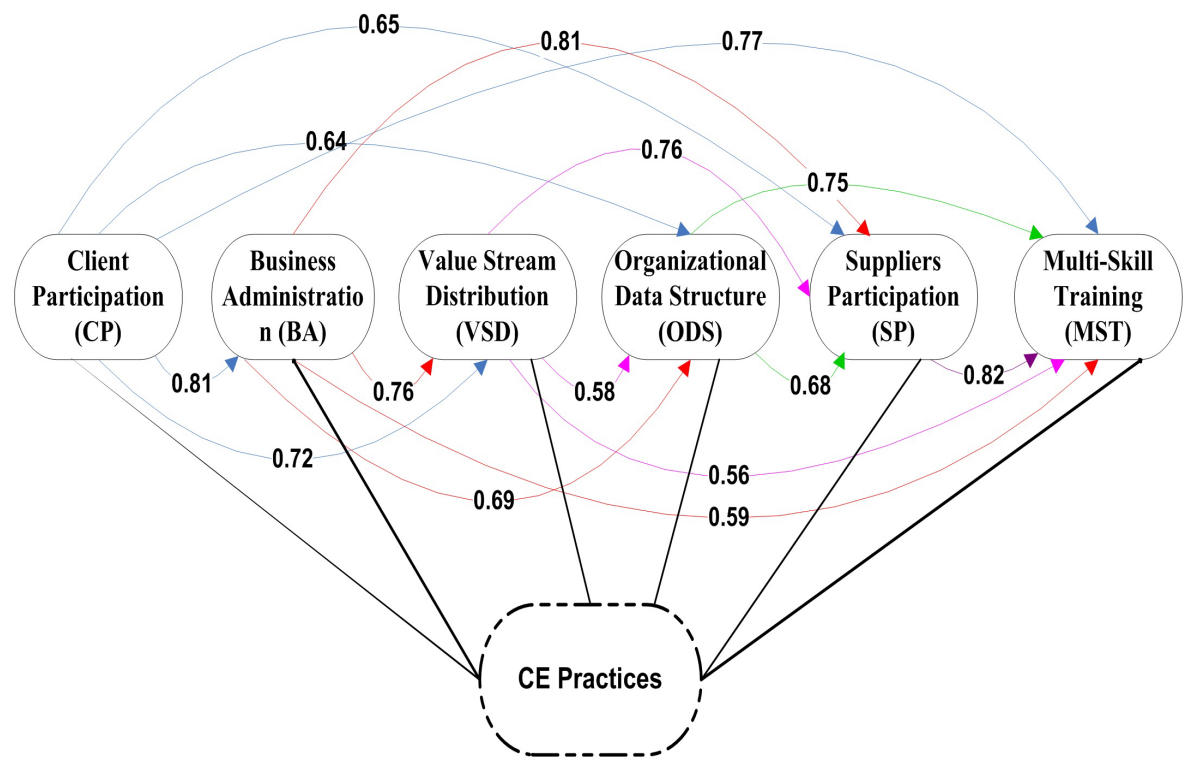

Figure 5. Estimates of the relations for the wood and furniture sectors.

\section{System Dynamics and Validation}

System dynamics (SD) models are diagrams that consisting of symbols and equations. The objective of SD modeling is to validate if the system is stable or not, and to evaluate if the system output increases, decreases or constant over time. One proven policy to compete and win in the dynamic automotive market is the one due to Toyota, which is widely discussed by Morgan and Liker [24]. This section provided a system dynamic model of the proposed conceptual model of CE practices and research hypotheses of this research as shown in Figure 6.

The equations used in the Stock-Flow Diagram (SFD) for the first stock "CP" are: 


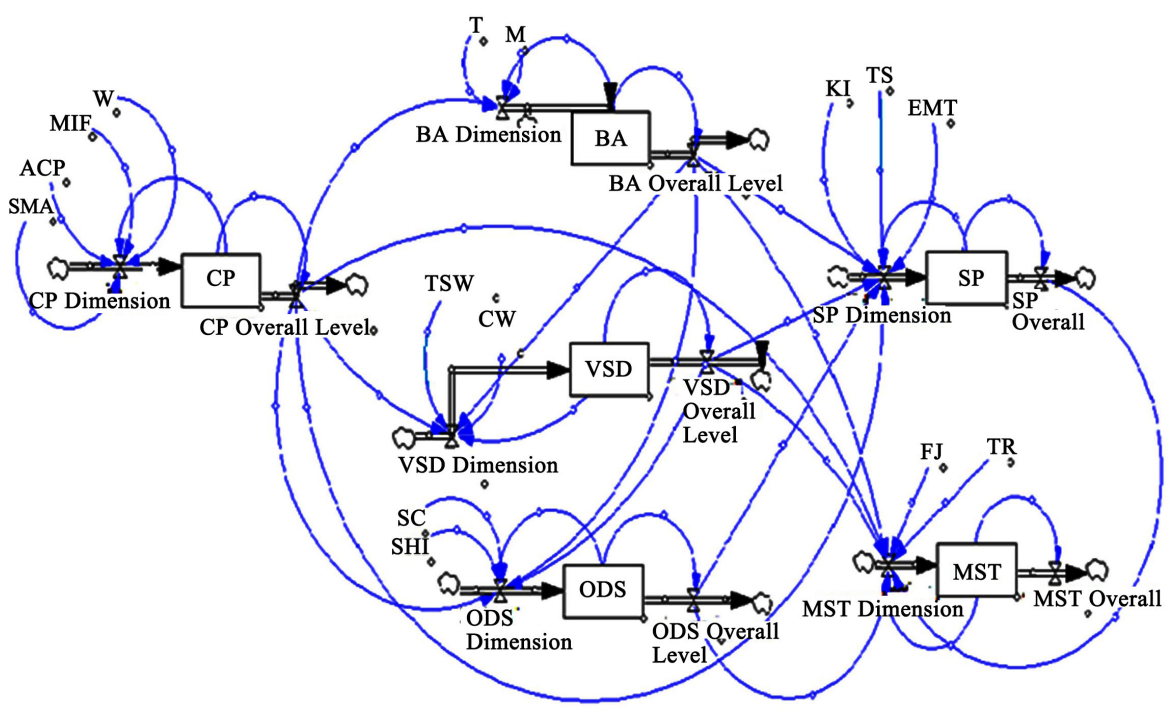

Figure 6. System dynamic model to CE practices.

$$
\begin{aligned}
& \mathrm{CP}(t)=\mathrm{CP}(t-d t)+d t\left(\mathrm{CP}_{\text {Dimension }}-\mathrm{CP}_{\text {Overall }}\right) \\
& \mathrm{CP}_{\text {Dimension }}=f(\mathrm{CP}, \mathrm{SMA}, \mathrm{ACP}, \mathrm{W}, \mathrm{MTF})
\end{aligned}
$$

A causal relation $y=f(x)$ means that the input variable (I) has some causal influence on the output variable $(y)$. The equations used in the SFD for the second stock "BA" are:

$$
\begin{aligned}
& \mathrm{BA}(t)=\mathrm{BA}(t-d t)+d t\left(\mathrm{BA}_{\text {Dimension }}-\mathrm{BA}_{\text {Overall }}\right) \\
& \mathrm{BA}_{\text {Dimension }}=f\left(\mathrm{BA}, \mathrm{T}, \mathrm{M}, C P_{\text {Dimension }}\right)
\end{aligned}
$$

The equations used in the SFD for the third stock "VSD" are:

$$
\begin{aligned}
& \operatorname{VSD}(t)=\operatorname{VSD}(t-d t)+d t\left(\mathrm{VSD}_{\text {Dimension }}-\mathrm{VSD}_{\text {Overall }}\right) \\
& \mathrm{VSD}_{\text {Dimension }}=f\left(\mathrm{VSD}, \mathrm{CP}_{\text {Overall }}, \mathrm{BA}_{\text {Overall }}, \mathrm{TSW}, \mathrm{CW}\right)
\end{aligned}
$$

The equations used in the SFD for the fourth stock "ODS" are:

$$
\begin{aligned}
& \operatorname{OSD}(t)=\operatorname{OSD}(t-d t)+d t\left(\mathrm{OSD}_{\text {Dimension }}-\mathrm{OSD}_{\text {Overall }}\right) \\
& \mathrm{OSD}_{\text {Dimension }}=f\left(\mathrm{OSD}, \mathrm{CP}_{\text {Overall }}, \mathrm{VSD}_{\text {Overall }}, \mathrm{BA}_{\text {Overall }}, \mathrm{SHI}, \mathrm{SC}\right)
\end{aligned}
$$

The equations used in the SFD for the fifth stock "SP" are:

$$
\begin{aligned}
& \mathrm{SP}(t)=\mathrm{SP}(t-d t)+d t\left(\mathrm{SP}_{\text {Dimension }}-\mathrm{SP}_{\text {Overall }}\right) \\
& \mathrm{SP}_{\text {Dimension }}=f\left(\mathrm{SP}, \mathrm{CP}_{\text {Overall }}, \mathrm{VSD}_{\text {Overall }}, \mathrm{BA}_{\text {Overall }}, \mathrm{OSD}_{\text {Overall }}, \mathrm{EMT}, \mathrm{KI}, \mathrm{TS}\right)
\end{aligned}
$$

The equations used in the SFD for the last stock "MST" are:

$$
\begin{aligned}
& \operatorname{MST}(t)=\operatorname{MST}(t-d t)+d t\left(\mathrm{MST}_{\text {Dimension }}-\mathrm{MST}_{\text {Overall }}\right) \\
& \mathrm{MST}_{\text {Dimension }}=f\left(\mathrm{MST}, \mathrm{CP}_{\text {Overall }}, \mathrm{VSD}_{\text {Overall }}, \mathrm{BA}_{\text {Overall }}, \mathrm{OSD}_{\text {Overall }}, \mathrm{SP}_{\text {Overall }}, \mathrm{FJ}, \mathrm{TR}\right)
\end{aligned}
$$

As shown in Figure 7 results of the SD simulation is graphically overlaid on the model. Scales with bar sliders are used to represent changes that can be made in constants. Running this System Dynamic model improved that the proposed conceptual model of CE practices and research hypotheses of this research is fit well and valid. 


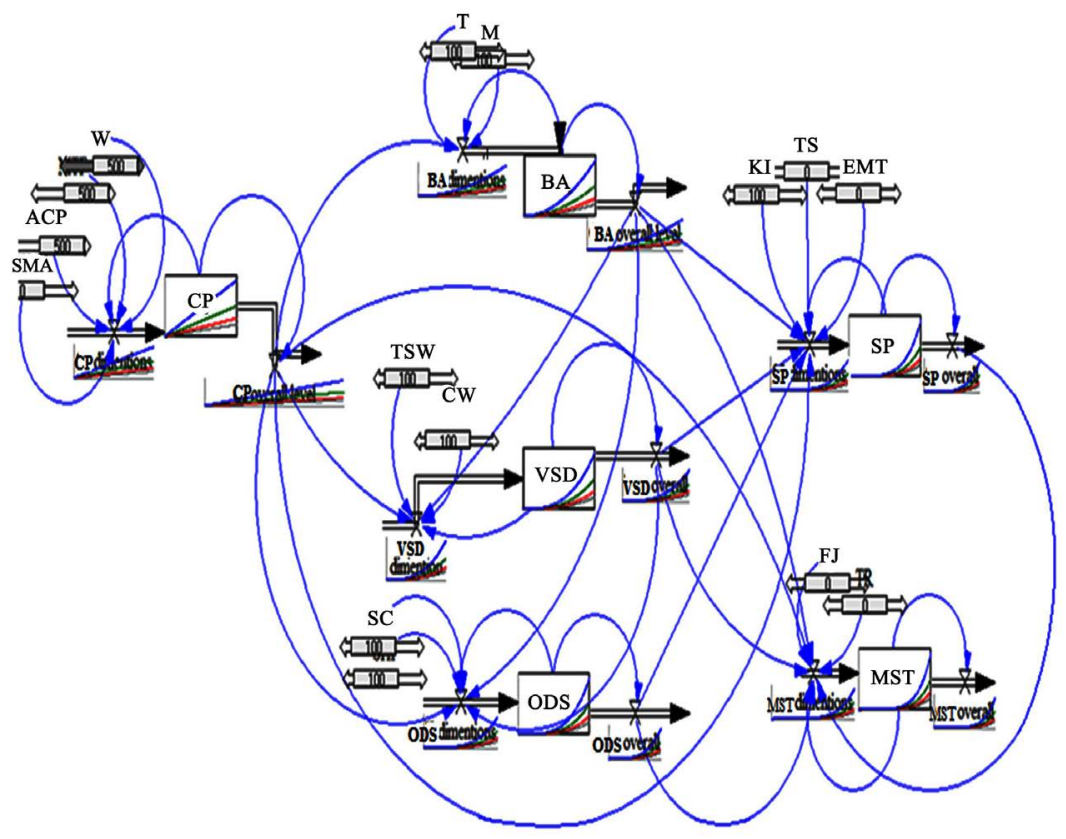

Figure 7. Graphical Outputs of the Model after Changing its Values.

\section{Conclusion}

The paper provided a statistical comparative investigation of the implementation of $\mathrm{CE}$ in Jordanian Industry that simplifies the implementation of CE in industry. A successful statistical comparative investigation of the implementation of $\mathrm{CE}$ in Jordanian Industry is provided; a system dynamic model validates results. This paper will contribute significantly to the literature in the field; the presented methodology is expected to enhance investigation related to the implementation of CE. That is expected to bridge the gap between academia and the applications of lean practice and CE. Moreover, the approach presented in this paper can facilitate to understand the implementation of CE practices in industries and assist in managing the challenges opposed to that.

\section{Acknowledgements}

Work presented in this paper is extracted from a master's thesis prepared by Ala'a AL-Habashneh under the supervision of Prof. Dr. Mohammad D. AL-Tahat; The University of Jordan approves the thesis in August 2016.

\section{Conflicts of Interest}

The authors declare no conflicts of interest regarding the publication of this paper.

\section{References}

[1] AL-Tahat, M.D. (2005) Optimizing of Work In Progress (WIP) in Kanban Controlled Production Lines. Dirasat. Engineering Sciences, 32, 123-132.

[2] Al-Momani, K.R., AL-Tahat, M.D. and Jaradat, E.T. (2006) Performance Measures 
for Improvement of Maintenance Effectiveness: A Case Study in King Abdullah University Hospital (KAUH). Proceeding of the International Conference on Service Systems and Service Management, Troyes, October 25-27 2006, 632-637. https://doi.org/10.1109/ICSSSM.2006.320535

[3] Al-Refaie, A. and AL-Tahat, M.D. (2014) Effects of Knowledge Management and Organization Learning on Firms' Performance. The Journal of Nature Science and Sustainable Technology (JNSST), 8, 369-390.

[4] AL-Tahat, M.D. and Al-Refaie, A. (2012) Activity-Based Cost Estimation Model for Foundry Systems Producing Steel Castings. Jordan Journal of Mechanical and Industrial Engineering (JJMIE), 6, 75-86.

[5] Dalalah, D., AL-Tahat, M.D. and Bataineh, K. (2012) Mutually Dependent Multi-criteria Decision Making. Fuzzy Information and Engineering, 4, 195-216. https://doi.org/10.1007/s12543-012-0111-3

[6] Al-Tahat, M.D., Abdul Jawwad, A.K.M. and Abu Nahleh, Y.L. (2013) Ordinal Logistic Regression Model of Failure Mode and Effects Analysis (FMEA) in Pharmaceutical Tabletting Tools. Engineering Failure Analysis, 27, 322-332. https://doi.org/10.1016/j.engfailanal.2012.08.017

[7] Al-Tahat, M.D. and Rawabdeh, I.A. (2008) Stochastic Analysis and Design of CONWIP Controlled Production Systems. Journal of Manufacturing Technology Management, 19, 253-273. https://doi.org/10.1108/17410380810847945

[8] Aljanaideh, O., AL-Tahat, M.D. and Al Janaideh, M. (2016) Rate-Bias-Dependent Hysteresis Modeling of a Magnetostrictive Transducer. Microsystem Technologies. 22, 883-892. https://doi.org/10.1007/s00542-015-2566-8

[9] Chouet, S.-Y., Trappey, A., Pokojski, J. and Smith, S. (2009) Global Perspective for Competitive Enterprise, Economy and Ecology. Proceedings of the 16th ISPE International Conference on Concurrent Engineering. In: Rajkumar, R. Ed., Advanced Concurrent Engineering, Springer, Switzerland, 267-279.

https://doi.org/10.1007/978-1-84882-762-2

[10] Herder, P.M. and Weijnen, M.P.C. (2000) A Concurrent Engineering Approach to Chemical Process Design. International Journal of Production Economics, 64, 311-318. https://doi.org/10.1016/S0925-5273(99)00068-7

[11] Yassine, A. and Braha, D. (2003) Complex Concurrent Engineering and the Design Structure Matrix Method. Concurrent Engineering, 11, 165-176. https://doi.org/10.1177/106329303034503

[12] Moges, A. (2007) Concurrent Engineering and Implementation a Case Study IN Addis Engineering Center. Doctoral Dissertation, Addis Ababa University, Ethiopia.

[13] Anderson, J.C. and Gerbing, D.W. (1988) Structural Equation Modeling in Practice: A Review and Recommended Two-Step Approach. Psychological Bulletin, 103, 411-423. https://doi.org/10.1037//0033-2909.103.3.411

[14] Wang, J.H., Chang, Y.C. and Chiu, W.H. (2013) Customer Involvement in the Process Innovation: Benchmarking. International Journal, 17, 180-194.

[15] Willaert, S.S., De Graf, R. and Minderhoud, S. (1998) Collaborative Engineering: A Case Study of Concurrent Engineering in a Wider Context. Journal of Engineering and Technology Management, 15, 87-109. https://doi.org/10.1016/S0923-4748(97)00026-X

[16] Anonymous, A. (1992) CAD/CAM Planning Organizing for Concurrent Engineering. Computer-Aided Engineering, 7-11. 
[17] Skalak, S. (2002) Implementing Concurrent Engineering in Small Companies. CRC Press, Boca Raton, FL.

[18] Handfield, R.B. (1993) The Role of Materials Management in Developing Time Based Competition. International Journal of Purchasing and Materials Management, 29, 2-10. https://doi.org/10.1111/j.1745-493X.1993.tb00255.x

[19] Rea, L.M. and Parker, R.A. (2005) Designing and Constructing Survey Research. Jossey-Bass, San Francisco, CA.

[20] Cronbach, L. (1951) Coefficient Alpha and the Internal Structure of Tests. Psychometrica, 16, 297-334. https://doi.org/10.1007/BF02310555

[21] Chadha, S.K. and Kapoor, D. (2009) Effect of Switching Cost, Service Quality and Customer Satisfaction on Customer Loyalty of Cellular Service Providers in Indian Market. IUP Journal of Marketing Management, 8, 23.

[22] Tillman, P., Ballard, G., Tzortzopolous, P. and Formosa, C. (2012) How Integrated Governance Contributes to Value Generation-Insights from an IPD Case Study. Proceedings of the 20th Annual Conference of the International Group for Lean Construction. San Diego, CA, 18-20 July 2012.

[23] Luger, L., Butler, J. and Winchm G. (2013) Infrastructure and Manufacturing: Their Evolving Relationship. Manchester Business School, Manchester.

[24] Morgan, J.M. and Liker, J.K. (2006) The Toyota Product Development System. Productivity Press, New York. https://doi.org/10.4324/9781482293746 